NATIONAL AERONAUTICS AND SPACE ADMINISTRATION

PROPOSED JOURNAL ARTICLE

THE VANADIUM-GALLIUM SYSTEM IN THE REGION OF/V 3 Ga

by John J. Fischer ${ }^{1}$ and Hubert B. Probst

Lewis Research Center -

Cleveland, Ohio

GPO PRICE \$

CFSTI PRICE(S)\$

Hard copy $(\mathrm{HC})$

Microfiche (MF) .SO-

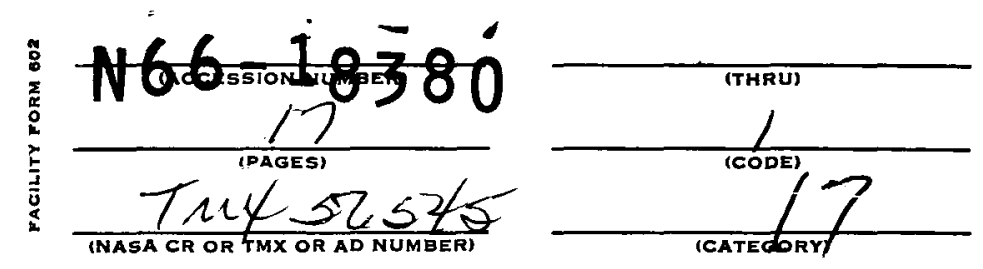

ff 653 July 65

Prepared for

Journal of the Less-Common Metals

April 15, 1965 


\section{THE VANADIUM-GALLIUM SYSTEM IN THE REGION OF $V_{3} \mathrm{Ga}$}

By John J. Fischer' ${ }^{\prime}$ and Hubert B. Probst

Lewis Research Center

National Aeronautics and Space Administration

Cleveland, Ohio

ABSTRACT

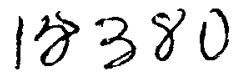

Melted samples were studied by X-ray diffraction and metallographic techniques after slow cooling from $1100^{\circ} \mathrm{C}$. The superconducting $V_{3}$ Ga phase was found to exist over a very limited compositional range. $V_{3}$ Ga exists in equilibrium: with either $\mathrm{V}_{6} \mathrm{Ga}_{5}$ or a vanadium solid solution depending on composition. The microstructures of samples near 75 atomic percent vanadium $\left(V_{3} G a\right)$ were essentially identical whether compositions were slightly hypostoichiometric or slightly hyperstoichiometric. Both $\mathrm{V}_{6} \mathrm{Ga}_{5}$ and the vanadium solid solution are nonsuperconducting at $4.2^{\circ} \mathrm{K}$.

\section{INTRODUCTION}

The vanadium-gallium ( $V-G a)$ system is of particular interest because it contains the superconducting compound $V_{3} G a$. In reference 1 , the critical field, $H_{C}$, at $0^{\circ} \mathrm{K}$ for this compound is estimated to be in excess of 500 ki logauss. Although superconductivity properties of $V_{3}$ Ga have been presented in the literature, little metallurgical information is available. In addition to $V_{3} G a$, the compunds $V_{5} G a_{3}, V G a, V_{6} G a_{5}$, and $V_{2} G a_{5}$ have been reported (see refs. 2 to 5 ).

$V_{3} G a$ has a cubic beta-tungsten type structure, and several authors (refs. 1, 6, and 7) have alluded to the fact that this compound exists as a solid solution over a wide compositional range (66 to 80 atomic percent $V$ ). On the other hand, reference 8 reports a constant lattice parameter for $V_{3} G a$

'Present Affiliation: international Nicke! Company, Paul D. Merica Research Laboratory, Suffern, New Yor 
within the composition range of 75 to 83 atomic percent vanadium and the presence of a second phase in the microstructure of such samples. These observations are indicative of 1 imited solubility. Reference 5 also reports limited solubility of approximately 0.5 atomic percent at $800^{\circ} \mathrm{C}$. Thus, there would appear to be some question as to the true compositional limits of the $V_{3}$ Ga phase.

$\mathrm{V}_{5} \mathrm{Ga}_{3}$ is reported to be stable only in the temperature range from $935^{\circ}$ to $1195^{\circ} \mathrm{C}$ (ref. 5); however, no structural information is available. Reference 5 discusses a VGa phase with a superlattice $\alpha-F e$ structure, while reference 4 reports a $V_{6} G_{5}$ phase as hexagonal. Because of the proximity of the compositions of these phases and the possibility of ambiguous $X$-ray data, it is not possible at this time to clearly state that these are two distinct compounds. The $\mathrm{V}_{2} \mathrm{Ga}_{5}$ compound is reported (ref. 4) to have a tetragonal crystal structure (isostructural with $\mathrm{Mn}_{2} \mathrm{Hg}_{5}$ ) and to melt peritectically at $1085^{\circ} \mathrm{C}$

The objectives of this investigation were to obtain information regarding the solubility range of $V_{3} G a$, to determine the phases in equilibrium with $V_{3} G a$, and to ascertain the presence or absence of superconductivity in these phases. To this end, compositions were prepared by melting under an argon atmosphere. In an attempt to obtain equilibrium structures, all samples were annealed at $1100^{\circ} \mathrm{C}$ for $1 \frac{1}{2}$ hours and slow cooled. Chemical analysis, X-ray diffraction patterns, and microstructures were obtained for each sample. Selected samples were tested for superconductivity at $4.2^{\circ} \mathrm{K}$.

\section{APPARATUS AND PROCEDURE}

The vanadium and gallium used in this investigation were in chunk form with purities of 99.83 weight percent vanadium and 99.99 weight percent gallium, 
respectively. All compositions were melted in yttria-stabilized zirconia boats. No evidence of a reaction between the zirconia boats and the charge was found. Melting was accomplished in a tungsten resistance furnace that was first evacuated to a pressure of $10^{-5}$ millimeter of mercury and then backfilled with high-purity argon to a pressure of $500 \mathrm{millimeters}$ of mercury.

The charge was heated to a temperature where 1 iquefaction appeared complete ( 1600 to $1800^{\circ} \mathrm{C}$ depending on composition) as judged by visual examination through an optical pyrometer. The specimens were held at the liquefaction temperature for $1 / 2$ hour and then cooled at a rate of approximately $20^{\circ} \mathrm{C}$ per minute. The samples were then annealed under an argon atmosphere at $1100^{\circ} \mathrm{C}$ for $\mathrm{l} \frac{1}{2}$ hours followed by a slow cool $\left(20^{\circ} \mathrm{C} / \mathrm{min}\right)$. Chemical analyses (both vanadium and gallium) and $X$-ray diffraction patterns were taken of all samples after annealing. Diffractometer patterns were taken after grinding the samples to -325 mesh powder. Nickel-filtered copper $K_{a}$ radiation was used with a scanning speed of $1 / 8^{\circ}$ per minute. Lattice constants were obtained from the X-ray diffraction patterns using a leastsquare analysis programed for the 7090 computer.

The superconductivity results were obtained from electrical resistivity measurements (voltage drop technique with sensitivity of $10^{-8}$ volt) at $4.2^{\circ} \mathrm{K}$. Microhardness measurements were made using a diamond indenter with a 100-gram load. The values are reported as diamond pyramid hardness (DPH) numbers.

\section{RESULTS AND DISCUSSION}

The compositions investigated are listed in table l. For samples containing from 52.7 to 74.8 atomic percent vanadium, the only phases present were $V_{6} G_{5}$ and $V_{3} G a$. All lines of $X$-ray patterns could be ascribed to either $V_{6} G a_{5}$ or $V_{3} G a$ with the $V_{3} G a$ lines increasing in intensity as the 
vanadium content increased.

The sample containing 52.7 atomic percent vanadium consisted primarily of $\mathrm{V}_{6} \mathrm{Ga} 5$ with a small amount of $\mathrm{V}_{3} \mathrm{Ga}$ present as a second phase. The microhardness of $\mathrm{V}_{6} \mathrm{Ga}_{5}$ was measured as $1000 \mathrm{DPH}$. The chemical analysis indicates this sample is within the limits reported for $\mathrm{V}_{6} \mathrm{Ga}_{5}$ in reference 4 . The presence of $\mathrm{V}_{3} \mathrm{Ga}$, however, indicates that the actual composition of the $\mathrm{V}_{6} \mathrm{Ga}_{5}$ compound is less than $\mathbf{5 2 . 7}$ atomic percent vanadium.

TABLE 1. - SAMPLE COMPOSITIONS

\begin{tabular}{|c|c|c|c|c|}
\hline \multicolumn{2}{|c|}{$\begin{array}{c}\text { As-mixed composition, } \\
\text { atomic percent }\end{array}$} & \multicolumn{2}{|c|}{$\begin{array}{l}\text { Resulting composition } \\
\text { after melting followed } \\
\text { by } 1100^{\circ} \text { c }, 1 \frac{1}{2} \text { hour } \\
\text { anneal, } \\
\text { atomic percent }\end{array}$} & \multirow[t]{2}{*}{ Phases present } \\
\hline Vanadium & Gallium & Vanad ium & Gallium & \\
\hline 51 & 49 & 52.7 & 47.2 & $\mathrm{~V}_{6} \mathrm{Ga}_{5}+\mathrm{V}_{3} \mathrm{Ga}$ \\
\hline 70 & 30 & 69.4 & 30.6 & $\mathrm{~V}_{6} \mathrm{Ga}_{5}+\mathrm{V}_{3} \mathrm{Ga}$ \\
\hline 73 & 27 & 74.5 & 25.3 & $V_{3} G a+v_{6} \bar{G} a_{5}$ \\
\hline 75 & 25 & 74.8 & 25.1 & $\mathrm{~V}_{3} \mathrm{Ga}+\mathrm{V}_{6} \mathrm{Ga}_{5}$ \\
\hline 74 & 26 & 76.2 & 23.4 & $V_{3} G a+V-G a$ solution \\
\hline 80 & 20 & 77.0 & 20.8 & $V-G a$ solution $+V_{3} G a$ \\
\hline 85 & 15 & 85.6 & 14.3 & V-Ga solution \\
\hline
\end{tabular}

The compound $\mathrm{V}_{6} \mathrm{Ga}_{5}$ (theoretical composition, 54.54 atomic percent vanadium) has been previously reported by two investigators (refs. 3 and 4 ). In reference 4 , its composition is given as $54 \pm 2$ atomic percent vanadium; $V_{6} \mathrm{Ga}_{5}$ is reported to be hexagonal with lattice parameters of $a_{0}=8.496 \pm 0.001$ angstroms and $c_{0}=5.174 \pm 0.001$ angstroms. Whether this is the same compound reporied iñ reference 5 as $V G a$ is not clear at this time. The X-ray results 
of the present investigation are in agreement with those of reference 4; therefore, the compound in the vicinity of 50 atomic percent vanadium is referred to as $\mathrm{V}_{6} \mathrm{Ga}_{5}$ in this paper.

The microstructure of the sample containing 69.4 atomic percent vanadium is shown in figure 1. An X-ray pattern obtained from this sample at $1127^{\circ} \mathrm{C}^{1}$ showed only $V_{6} G_{5}$ and $V_{3} G a$ phases present, while at $1327^{\circ} \mathrm{C}$ only $V_{3} G a$ lines were detected. Upon cooling to room temperature, the $\mathrm{V}_{6} \mathrm{Ga}_{5}$ lines reappeared. These results failed to show the presence of any high-temperature phase such as $\mathrm{V}_{5} \mathrm{Ga}_{3}$ reported by reference 5. Thus, it would appear that the microstructure of figure $l$ is the result of either a eutectic or peritectic reaction occurring between $1127^{\circ}$ and $1327^{\circ} \mathrm{C}$. The microhardness measurements indicate that the white phase of figure $l$ is $V_{3}$ Ga. This phase exhibited a hardness of $920 \mathrm{DPH}$, which was identical to that measured for $V_{3}$ Ga (discussed below).

As mentioned in the INTRODUCTION, there are conflicting views in the literature regarding the solubility limits of the $V_{3} G a$ phase. Attempts to obtain single-phase $V_{3} G$ a samples in this study were unsuccessful. Samples containing 74.5, 74.8, 76.2, and 77.0 atomic percent vanadium were examined, and none of these were single-phase materials. Typical microstructures of samples near the stoichiometric composition are shown in figures 2 and 3 . A comparison of figures 2 and 3 reveals that essentially the same microstructure results regardless of whether the composition is slightly hypostoichiometric (atomic percent vanadium < 75, fig. 2) or hyperstoichiometric (atomic percent vanadium > 75, fig. 3 ). Evidence of a second phase is offered in figure 4. This electron photograph of the 74.8 atomic percent vanadium sample magnified 14,000 times definitely shows the particles of a second phase.

'High-temperature X-ray patterns were obtained using a helium atmosphere. 
Quenching of near-stoichiometric samples from the annealing temperature of $1100^{\circ} \mathrm{C}$ resulted in essentially the same microstructure, although a somewhat finer distribution resulted. Reference 5 also shows a second phase present in near-stoichiometric compositions quenched from $800^{\circ} \mathrm{C}$. However, the distribution of the second phase differs from that shown in figures 2 and 3 . This difference may be due to the lower temperature and long annealing times ( $800 \mathrm{hr}$ ) used in reference 5 .

$X$-ray diffraction of these near-stoichiometric compositions showed $V_{3} G a$ to be the major phase present. For hypostoichiometric compositions, $V_{6}{ }^{G a}$ lines were identified in the X-ray patters; while at hyperstoichiometric compositions, vanadium lines were present.

The lattice parameter of $V_{3} G a$ also remained constant at $4.8165 \pm 0.0015$ angstroms for both hypostoichiometric and hyperstoichiometric compositions. This is in agreement with the value given in reference 8 of $4.816 \pm 0.002$ angstroms. The constancy of the lattice parameter observed here, the identification of second phases as equilibrium phases (either $V_{6} G a_{5}$ or vanadium), and the characteristic microstructures of near-stoichiometric compositions all suggest that single-phase $V_{3} G a$ exists over a very limited compositional range. Microhardness measurements of the light matrix phase of figures 2 and $3\left(V_{3} G a\right)$ gave a value of $920 \mathrm{DPH}$.

A sample containing 85.6 atomic percent vanadium was examined metallographically and by $X$-ray diffraction and found to be a single-phase vanadium solid solution. The lattice parameter of this solid solution is 3.038 angstroms compared to 3. 028 angstroms for pure vanadium (ref. 9).

The sample containing 77.0 atomic percent vanadium definitely contained $V_{3} G a$ in addition to the vanadium solid solution. The chemical analysis of thas sample (Table 1) suggests that some contamination has occurred. Subsequent 
analysis revealed approximately 1 weight percent oxygen. The sample containing 76.2 atomic percent vanadium also consists of $V_{3} G a$ and the vanadium solid solution.

\section{SUPERCONDUCTIVITY MEASUREMENTS}

The sample containing 52.7 atomic percent vanadium (primarily $\mathrm{V}_{6} \mathrm{Ga}_{5}$ ) was tested for superconductivity at $4.2^{\circ} \mathrm{K}$ and found to be normal. Reference 4 reported $\mathrm{V}_{6} \mathrm{Ga}{ }_{5}$ to be normal to $2.1^{\circ} \mathrm{K}$.

The sample containing 85.6 atomic percent vanadium was also tested and found to be normal at $4.2^{\circ} \mathrm{K}$. This result indicates that the critical temperature, $T_{C}$, of vanadium is lowered more than $1^{\circ} \mathrm{K}$ by the addition of 14.3 atomic percent gallium in solution, based on a $T_{c}$ of $5.3^{\circ} \mathrm{K}$ reported for pure vanadium (ref. 10).

These results indicate that the phases in equilibrium with $V_{3} G a$ are normal at $4.2^{\circ} \mathrm{K}$. Therefore, for near-stoichiometric compositions at $4.2^{\circ} \mathrm{K}$, the

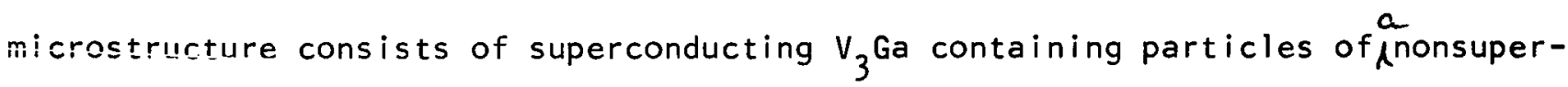
conducting second phase. These particles are generally of a continuous nature as opposed to isolated particles (figs. 2 to 4 ), and as such govern the size of the superconducting $V_{3} G a$ paths. Structures with the $V_{3}$ Ga continuous path of the order of 2000 to 5000 angstroms wide have been observed in connection with this study. Critical field enhancement by decreasing the dimensions of the superconducting phase has been obtained in aluminum-lead composites (ref. 11) and a niobium-thorium eutectic alloy (ref. 12). In the case of $V_{3} G a$, control of this dimension by heat treatment and/or compositional variations might offer a means of maximizing critical fields. 


\section{SUMMARY OF RESULTS}

The following are the major results of this investigation:

1. The $V_{3}$ Ga phase exists over a very limited compositional range near the stoichiometric composition.

2. The phases coexisting with $\mathrm{V}_{3} \mathrm{Ga}$ at room temperature are $\mathrm{V}_{6} \mathrm{Ga}_{5}$ for hypostoichiometric compositions and vanadium with gallium in solid solution for hyperstoichiometric compositions.

3. Both $\mathrm{V}_{6} \mathrm{Ga}_{5}$ and a vanadium solid solution containing 14.3 atomic percent gallium are normal at $4.2^{\circ} \mathrm{K}$.

4. The microstructural appearances of slightly hypostoichiometric and hyperstoichiometric compositions are essentially identical, with a second phase, either $V_{6} G_{5}$ or gallium saturated vanadium, present as precipitate particles in the $V_{3}$ Ga matrix. 
1. Wernick, J.H.: Evidence for a Critical Magnetic Field in Excess of 500 Kilogauss in the Suerconducting V-Ga System. High Magnetic Fields, H. Kolm, ed., M.I.T. Press and John Wiley and Sons, Inc., 1962.

2. Schubert, K., et al.: Einige Strukturdaten Metallischer Phasen (7). (Structural Data on Metallic Phases, VII.) Naturwissenschaften, vol. 49, 1962, p. 57.

3. Schubert, K., et al.: Einige Strukturdaten Metallischer Phasen (8). (Structural Data on Metallic Phases, VIII.) Naturwissenschaften, vol. 50, no. 2,1963, p. 41 .

4. Van Vucht, J.H.N. ; Bruning, H.A.C.M.; and Donkersloot, H.C.: New Compounds Related to the Superconductors $\mathrm{V}_{3} \mathrm{Ga}$ and $\mathrm{Nb}_{3} \mathrm{Sn}$. Phys. Letters, vol. 7, no. 5, Dec., 15, 1963, p. 297.

5. Savitskii, E.M.; Kripyakevich, P.I.; Baron, V.V.; and Efmov, Yu. V.: Phase Diagram for the Vanadium-Gallium System. Zh. Neorgan. Khim., vol. 9, no. 5, 1964, pp. 1155-1157.

6. Geller, S.: A Set of Effective Coordination-Number (12) Radii for the B-Tungsten Structure Elements. Acta. Cryst., vol. 9, 1956, pp. 885-889.

7. Blumberg, W.E.; Eisinger, J; Jaccarino, V.; and Matthias, B. T.: Correlations Between Superconductivity and Nuclear Magnetic Resonance Properties. Phys. Rev. Letters, vol. 5, no. 4, Aug. 15, 1960, pp. 149-152.

8. Wood, E. A.; Compton, V. B.; Matthias, B.T.; and Corenzwit, E.: $\beta$-Tungsten Structure of Compounds Between Transition Elements and Aluminum, Gallium and Antimony. Acta. Cryst., vol. 11, 1958, pp. 604-606.

9. Taylor, A.: X-Ray Metallography. John Wiley \& Sons, Inc., 1961, p. 973. 10. Roberts, B. W.: Superconductive Materials and Some of Their Properties. Rep. 63-RL-3252M, Generai Eiectric Res. Lab., Mar. 1963. 
11. Seraphim, D.P.; d'Heurle, F.M.; and Heller, W.R.: Coherent Superconducting Behavior of Two Metals (Al-Pb) in a r.Synthetic Filamentary Structure. Appl. Phys. Letters, vol. 1, no. 4, 1962, pp. 93-95.

12. Cline, H.E.; Rose, R.M.; and Wulff, J.: Niobium-Thorium Eutectic Alloy as a High-Field High-Current Superconductor. Journ. Appl. Phys., vol. 34, no. 6 , June 1963, pp. 1771-1774. 


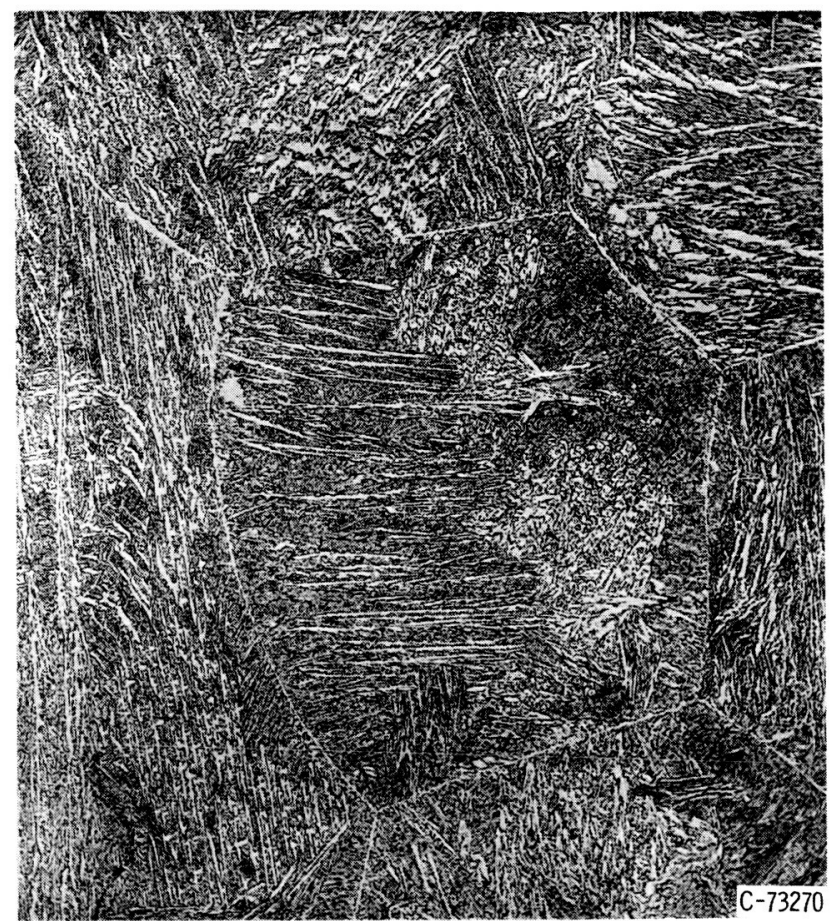

Figure 1. - Microstructure of sample containing 69.4 atomic percent vanadium. $\mathrm{V}_{3} \mathrm{Ga}$ (white) $+\mathrm{V}_{6} \mathrm{Ga}_{5}$. Etchant, $4 \mathrm{H}_{2} \mathrm{O}-3 \mathrm{HNO}_{3}-\mathrm{IHF} ; \mathrm{Xl} 00$.

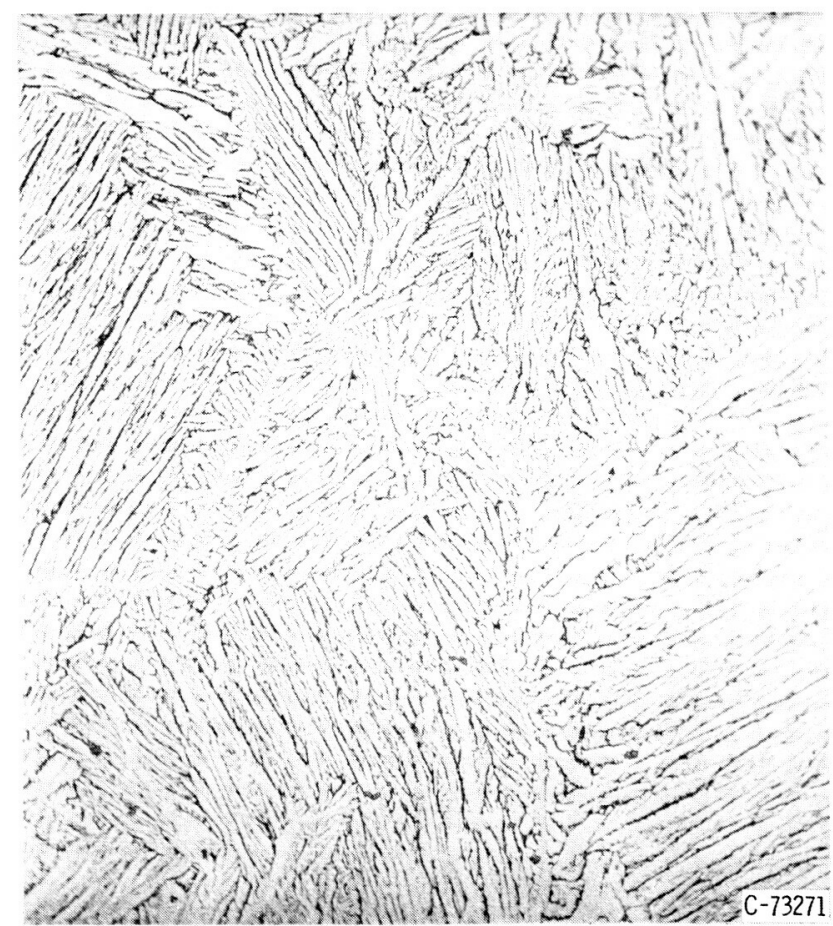

Figure 2. - Microstructure of sample containing 74.8 atomic percent vanadium. Primary phase, $V_{3} G a$ iwritite); seconndary phouse, $V_{6} G_{5}$. Etchant, $4 \mathrm{H}_{2} \mathrm{O}-3 \mathrm{HNO}_{3}-\mathrm{IHF} ; \mathrm{X} 250$. 


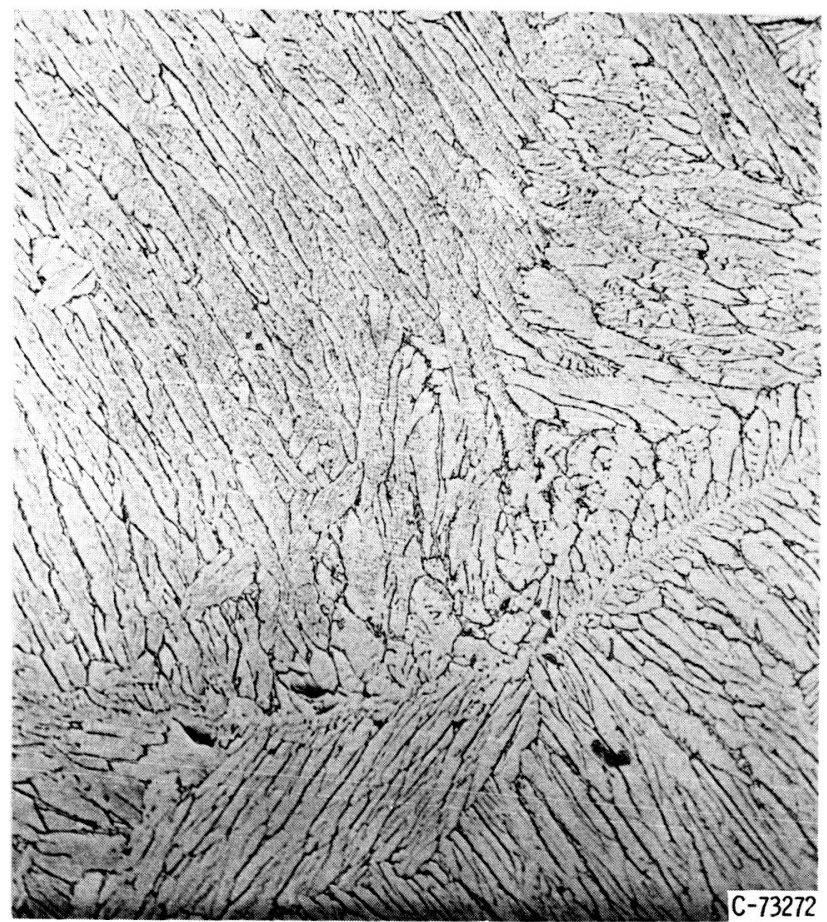

Figure 3. - Microstructure of sample containing 76.2 atomic percent vanadium. Primary phase, $\mathrm{V}_{3} \mathrm{Ga}$ (white); secondary phase, $\mathrm{V}-\mathrm{Ga}$ solution. Etchant, $4 \mathrm{H}_{2} \mathrm{O}-3 \mathrm{HNO}_{3}-\mathrm{IHF} ; \mathrm{X} 250$.

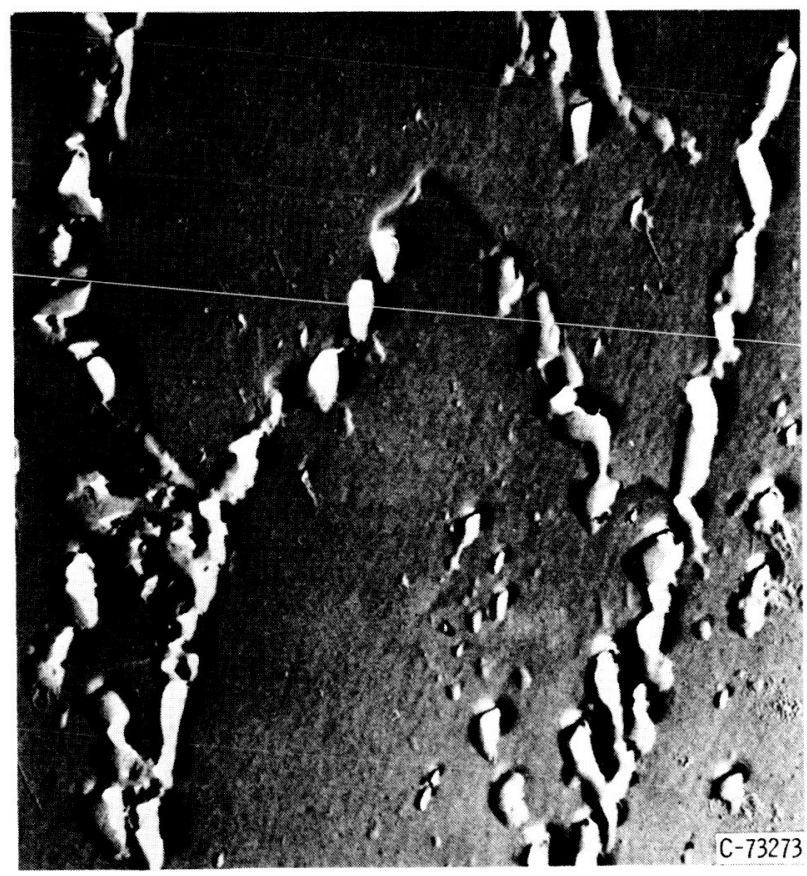

Figure 4. - Electron micrograph of sample containing 74.8 atomic percent vanadium. Primary phase, $\mathrm{V}_{3} \mathrm{Ga}$ matrix; second phase, $\mathrm{V}_{6} \mathrm{Ga}_{5}$. $\mathrm{X} 14,000$. 